\title{
Workplace Stress and Job Satisfaction among Biologics Development Professionals
}

\author{
Hui Xiang1*, Suzanne Coleman1, Mark Johannsson'1, Ronald Bates ${ }^{2}$ \\ ${ }^{1}$ Arizona School of Health Sciences, A.T. Still University, Mesa, USA \\ ${ }^{2}$ Bristol-Myers Squibb Company, East Syracuse, USA \\ Email: ${ }^{\text {hxgmtlac@yahoo.com }}$
}

Received 20 May 2014; revised 30 June 2014; accepted 14 July 2014

Copyright (C) 2014 by authors and Scientific Research Publishing Inc.

This work is licensed under the Creative Commons Attribution International License (CC BY). http://creativecommons.org/licenses/by/4.0/

(c) (i) Open Access

\begin{abstract}
Workplace stress is a common problem with broad effects in professional life. This study aimed to understand how workplace stressors affect job satisfaction among biologics development professionals. A cross-sectional survey was conducted at a biologics development organization. Multiple linear regression analysis was performed using years of experience, ambiguity, job conflict, perceived control, social support, job demands, self-esteem, and self-rated workplace stress as independent variables and job satisfaction as dependent variable (response). The regression model indicated that the workplace stressors and their two-level interactions significantly predicted employees' job satisfaction, which explained $89 \%$ of the variance in level of job satisfaction $\left(R^{2}=\right.$ $0.89, F(17,16)=7.251, p=0.0001)$. The interaction between perceived control and job demand and interaction between self-rated stress and job conflict had the biggest effect size on job satisfaction. This model was further used in Monte Carlo simulation to predict the outcome of job satisfaction under different work conditions. The findings will help the management to develop strategies to improve employee job satisfaction.
\end{abstract}

\section{Keywords}

Workplace Stress, Job Satisfaction, Linear Regression, Monte Carlo Simulation

\section{Introduction}

Workplace stress has long been recognized as a common problem with broad effects. Its high prevalence is associated with costs to individuals and organizations [1] [2]. There are a variety of factors that cause stress (stressors) at the workplace, which include work load, responsibility, job insecurity, role ambiguity, conflict,

\footnotetext{
${ }^{*}$ Corresponding author.
} 
lack of control, emotional needs, lack of support, irregular working schedules, undefined roles, and lack of reward [3]-[7]. Based on the widely accepted stress theory, stress occurs based on the body's subjective appraisal of environmental situations, when one perceives that the demands from the environment cannot be met by available resources [8]-[10]. The demand control and support model states that workplace stress occurs when the job demands are high and the employee's latitude of control and received support on work is low [11] [12]. This model emphasizes the social determinants of workplace stress and attributes stress primarily to the structural and organizational aspects of the work environment. Workplace stress has broad adverse effects on both individuals and organizations. It reduces work performance, lowers job satisfaction and self-esteem, increases the risk of absenteeism and accidents, and negatively affects employees' health [6]. Different people may respond differently to the same stress conditions [13]-[15]. It is important to gain a better understanding on work stress and its effects on employee job satisfaction.

The purpose of this study was to measure workplace stress, and to assess how workplace stressors affect employee job satisfaction among professionals working at a biologics development organization. A research model (Figure 1) was proposed based on the demand control and support model. In the proposed model, the workplace stressors (exogenous observed variables) were grouped into five categories (or dimensions, which include job demand, ambiguity, job conflict, perceived control, and social support as latent variables), which were further grouped into two big categories (secondary latent variables), demands and resources. Demands are the working conditions that potentially lead to workplace stress, when they are excessive beyond one's personal limits and abilities [8]-[10]. Resources are the working conditions that potentially lead to workplace stress when they are insufficient or lacking. The endogenous observed variable in the proposed model was job satisfaction. A crosssectional survey was conducted among biologics development professionals to measure the different workplace stressors, reflected in demands and resources, as well as self-rated stress and job satisfaction. This group of professionals is involved in developing biological drugs and providing support in drug manufacture and approval throughout the lifecycle of the product. The survey results were analyzed statistically to determine the relationship between the workplace stressors and job satisfaction.

Measurements Independent Variables Dependent Variable

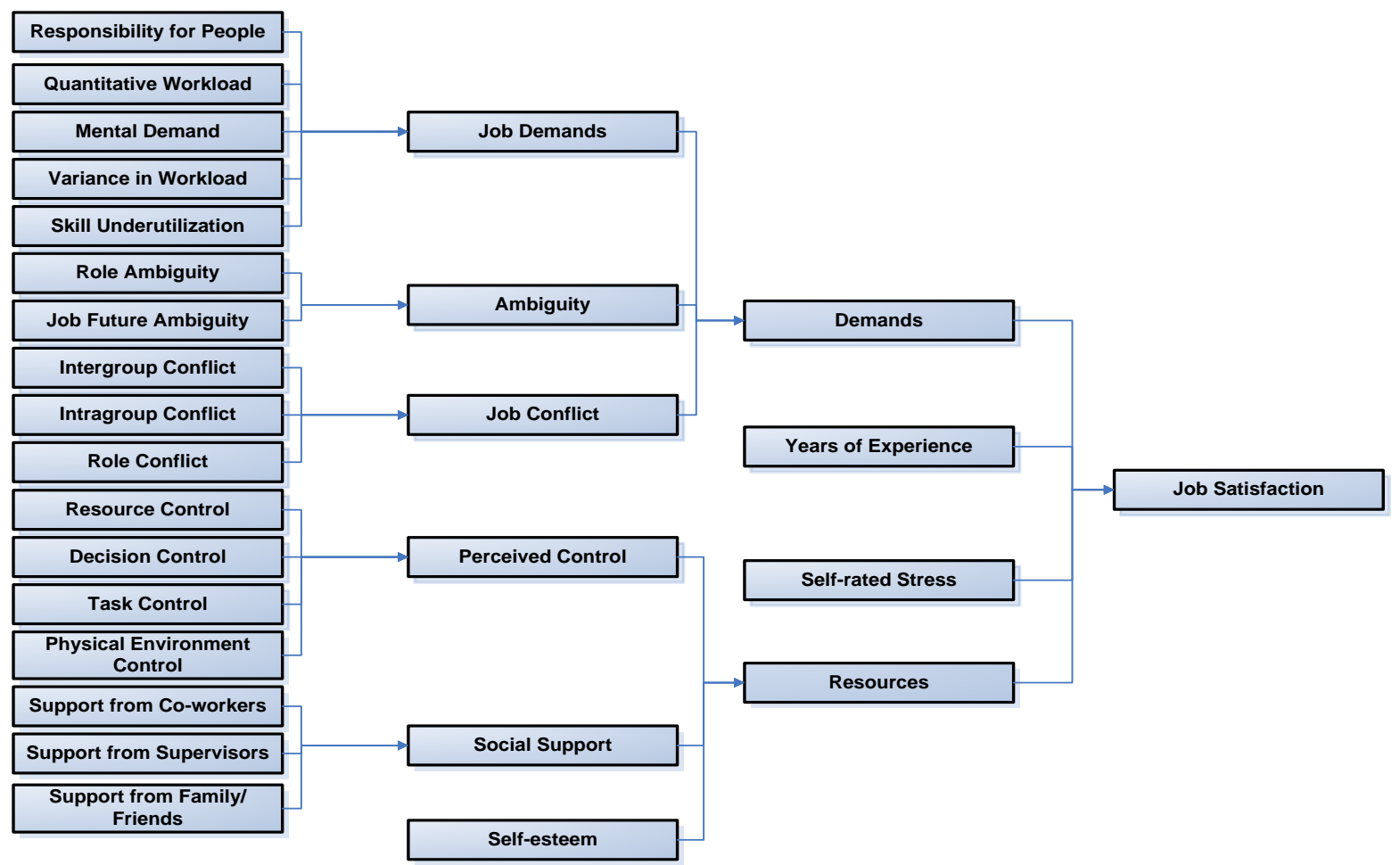

Figure 1. Schematic illustration of the proposed research model of workplace stress and job satisfaction. 
Evidence from previous studies revealed negative association between workplace stressors and job satisfaction in professionals such as nurses [3] [5] [7], teachers [4], and civil aviation workers [6] [16]. This study aimed to evaluate the effect of workplace stressors on job satisfaction among professionals working at a biologics development organization. With a work force of 110, this organization is actively involved in process development, assay development, product characterization, outsourcing management, and manufacturing support. The findings of this study would help the management at this organization to develop mitigations strategies to adjust working conditions in order to improve employee job satisfaction.

\section{Methods}

\subsection{Sample}

A cross-sectional survey was conducted to measure workplace stressors and job satisfaction. Participants were recruited from a biologics development organization with 110 employees. The questionnaire was built online at the eSurv website (http://esurv.org), and distributed electronically to the participants. All employees working part-time or full-time at this organization at the time of survey were qualified study participants. The exclusion criteria included temporary service contractors, such as janitors, consultants, etc. The study proposal was reviewed and approved by the A.T. Still University Institutional Review Board prior to study initiation.

The survey response was collected from April 15 to May 15, 2013. At the closing date of the survey, 42 responses were obtained from 110 employees. This represented a response rate of $38 \%$. Sample demographics are summarized in Table 1. Among the 42 respondents, 59\% were males, $79 \%$ were between the ages 31 and 50, $74 \%$ were individual contributors without supervisory responsibilities, and $50 \%$ had up to 10 years of working experience. This was consistent with the population demographics from which the samples were derived.

\begin{tabular}{|c|c|c|c|c|c|c|}
\hline & & & Frequency & Percent & Valid Percent & Cumulative Percent \\
\hline \multirow[t]{5}{*}{ Gender } & & Female & 15 & 36 & 37 & 37 \\
\hline & Valid & Male & 25 & 59 & 62 & 100 \\
\hline & & Total & 40 & 95 & 100 & \\
\hline & Missing & & 2 & 5 & & \\
\hline & Total & & 42 & 100 & & \\
\hline \multirow[t]{7}{*}{ Age Group } & & $21-30$ & 4 & 9 & 10 & 10 \\
\hline & & $31-40$ & 18 & 43 & 44 & 54 \\
\hline & Valid & $41-50$ & 15 & 36 & 37 & 90 \\
\hline & & $51-60$ & 4 & 9 & 10 & 100 \\
\hline & & Total & 41 & 98 & 100 & \\
\hline & Missing & & 1 & 2 & & \\
\hline & Total & & 42 & 100 & & \\
\hline \multirow[t]{3}{*}{ Role } & & Contributor & 31 & 74 & 74 & 74 \\
\hline & Valid & Manager & 11 & 26 & 26 & 100 \\
\hline & & Total & 42 & 100 & 100 & \\
\hline \multirow[t]{6}{*}{ Years of Experience } & & $0-10$ & 21 & 50 & 52 & 52 \\
\hline & & $11-20$ & 17 & 40 & 42 & 95 \\
\hline & Valid & $21-30$ & 2 & 5 & 5 & 100 \\
\hline & & Total & 40 & 95 & 100 & \\
\hline & Missing & & 2 & 5 & & \\
\hline & Total & & 42 & 100 & & \\
\hline \multirow[t]{7}{*}{ Function } & & Analytic & 15 & 36 & 37 & 37 \\
\hline & & Document & 3 & 7 & 7 & 45 \\
\hline & Valid & Process & 20 & 48 & 50 & 95 \\
\hline & & Project/ & 2 & 5 & 5 & 100 \\
\hline & & Total & 40 & 95 & 100 & \\
\hline & Missing & & 2 & 5 & & \\
\hline & Total & & 42 & 100 & & \\
\hline
\end{tabular}

"Percent” refers to the percentage of total responses that includes both valid and missing responses; "Valid Percent" refers to the percentage of valid responses; "Cumulative Percent” refers to the cumulative percentage of valid responses. 


\subsection{Instrument}

The survey instrument was an abbreviated version of the National Institute of Occupational Safety and Health (NIOSH) General Job Stress Questionnaire [17]. This survey instrument had been validated in previous studies to measure workplace stress [18] [19]. The instrument was modified to focus on the following workplace stressors: role ambiguity, job future ambiguity, intragroup conflict, intergroup conflict, role conflict, quantitative workload, variance in workload, mental demand, responsibility for people, skill underutilization, task control, physical environment control, resource control, decision control, social support from supervisor, social support from co-workers, social support from family/friends, and self-esteem. In addition, the items on job satisfaction were included. Self-rated stress was measured using the stress items in the Depression Anxiety Stress Scale-21 (DASS21) Questionnaire [20]. Both survey instruments were in the public domain, and permissions were not needed for use, as long as sources were appropriately referenced. The scores were computed based on the scoring keys of the instruments [17] [20].

\subsection{Reliability}

Internal reliability of the items was verified by computing the Cronbach's $\alpha$, which is summarized in Table 2. A value of 0.6 or higher is generally considered acceptable for early stage research [6]. Resource control and task control have low Cronbach's $\alpha$ values, -0.37 and 0.57 , respectively, while all other variables have Cronbach's $\alpha$ values above 0.6. The reference data from nurses [17] and the general adult population [21] were also summarized in Table 2.

Table 2. Descriptive and reliability statistics of measured results.

\begin{tabular}{|c|c|c|c|c|c|}
\hline \multirow{2}{*}{ Measurement } & \multirow{2}{*}{ Number of Items } & \multirow{2}{*}{ Mean } & \multirow{2}{*}{$S D$} & \multicolumn{2}{|c|}{ Cronbach's $\alpha$} \\
\hline & & & & This Study & Reference Data $^{\mathrm{a}}$ \\
\hline Role Ambiguity & 6 & 2.94 & 0.81 & 0.85 & 0.74 \\
\hline Role Conflict & 8 & 3.34 & 0.71 & 0.79 & 0.82 \\
\hline Intragroup Conflict & 8 & 2.78 & 0.68 & 0.74 & 0.86 \\
\hline Intergroup Conflict & 8 & 3.08 & 0.78 & 0.86 & 0.85 \\
\hline Job Future Ambiguity & 4 & 3.27 & 0.99 & 0.76 & 0.65 \\
\hline Resource Control & 2 & 3.25 & 0.54 & -0.37 & 0.82 \\
\hline Task Control & 8 & 3.19 & 0.51 & 0.57 & 0.85 \\
\hline Physical Environment Control & 2 & 3.03 & 0.90 & 0.64 & 0.79 \\
\hline Decision Control & 4 & 2.67 & 0.90 & 0.82 & 0.74 \\
\hline Support from Supervisor & 4 & 4.02 & 0.80 & 0.83 & 0.88 \\
\hline Support from Peer & 4 & 3.84 & 0.71 & 0.64 & 0.84 \\
\hline Support from Family/Friends & 4 & 4.44 & 0.56 & 0.67 & 0.85 \\
\hline Quantitative Workload & 11 & 3.79 & 0.67 & 0.87 & 0.85 \\
\hline Variance in Workload & 3 & 3.59 & 0.92 & 0.92 & 0.86 \\
\hline Skill Underutilization & 3 & 2.74 & 1.04 & 0.82 & 0.73 \\
\hline Responsibility for People & 4 & 2.70 & 1.09 & 0.86 & 0.62 \\
\hline Mental Demands & 5 & 4.16 & 0.74 & 0.72 & 0.75 \\
\hline Self-esteem & 4 & 3.97 & 0.61 & 0.82 & 0.85 \\
\hline Workplace Stress & 10 & 2.37 & 1.00 & 0.91 & $0.93^{\mathrm{b}}$ \\
\hline Job Satisfaction & 7 & 3.73 & 0.98 & 0.77 & 0.83 \\
\hline
\end{tabular}

All measurement results were converted to 1 - 5 scale, based on a method reported in “Transforming different Likert scales to a common scale,” by IBM [21]. Reference data of Cronbach’s $\alpha$ were from ${ }^{\mathrm{a}} 700$ Newfoundland nurses [17] or ${ }^{\mathrm{b}} 1794$ general adult UK population [21]. 


\subsection{Data Analysis}

All measurement results were converted to a 1 - 5 scale, based on a method reported by IBM [22]. The data type of year of experience was changed from nominal to scale by taking the midpoint of the categories, namely 5,15 , and 25 years were used for people with $0-10,11-20$, and 21 - 30 years of experience, respectively. None of the employees had over 30 years of experience. The data were analyzed using SPSS Statistics software version 22.0 (IBM, Armonk, NY) or JMP software version 10 (SAS Institute Inc., Cary, NC). The workplace stressors (observed exogenous variables) and derived latent variables (job demands, ambiguity, job conflicts, social support, and perceived control) were used as independent variables in data analyses, and the dependent variable (response) was level of job satisfaction. The demographic information served as control variables to compare the results from the different population groups, based on gender, age group, role in organization, years in the industry, and primary functional area.

The data were analyzed using descriptive statistics such as mean, standard deviation, standard error of mean, 95\% confidence interval, percentage, and frequency. Data were fitted using two-tailed Normal fitting first. The Normality was checked using Shapiro-Wilk W test. The null hypothesis $(\mathrm{Ho})$ posited that the data was from the Normal distribution; a $p$-value smaller than or equal to the significance level (0.05) rejects Ho. If the goodnessof-fit test failed $(p<0.05$ ), other continuous fitting was performed. The fitting with the smallest AICc (Akaike information criterion with correction of sample size) was selected. Inter-correlations of the variables were assessed using pairwise correlation analysis, and the resulting Pearson (product-moment) correlation coefficients were summarized in a correlation table (Table 3). Outliers were identified using Jackknife distance analysis.

The research hypothesis was tested with multiple linear regression analysis, which not only tested the statistical significance ( $p$-value) of the effect, but also quantified the effect size of the independent variables and their interactions on the responses. Multiple linear regression analysis was used to construct statistical models, using the independent variables as factors and dependent variables as responses. Model fit was assessed by both goodness of fit $\left(R^{2}\right.$ and adjusted $R^{2}$ ) and lack of fit indices, with significance ( $p$-value) set at 0.05 . Model significance was tested by multivariate ANOVA. Each factor and interaction pair was correlated with an estimated regression coefficient to form a term in the regression model. The significance of each term as a factor of the model was evaluated by $t$-test comparing the estimated coefficient to the standard deviation of that coefficient. Model terms with significant effects on the measured response were identified by a $p$-value of less than 0.05 of getting a greater $t$-ratio by chance. The model was refined to keep only the terms that have statistically significant effects ( $p$-value less than 0.05). The collinearity was assessed by the variable inflation factor (VIF), and the terms with VIF values of 8 and above were removed to avoid over fitting. Based on the regression model, prediction profiles were plotted to discern factor importance (indicated by the steepness of a trace), interactions (indicated by changes in trace slope or curvature in response to shifts in other parameter settings), and conditions that achieved a desired response.

The established regression model was used in Monte Carlo simulation to predict the level of job satisfaction with independent variables set under different scenarios. Two scenarios were simulated to illustrate the application of model. The first scenario was the current work condition, where the mean values and standard deviations of independent variables from the survey data were used. To compensate for the uncontrolled variations, the

Table 3. Pearson correlation of the variables $(n=42)$.

\begin{tabular}{lcccccccc}
\hline & 1 & 2 & 3 & 4 & 5 & 6 & 7 & 8 \\
\hline 1. Years of Experience & - & & & & & & & \\
2. Ambiguity & -0.271 & - & & & & & & \\
3. Job Conflict & 0.076 & 0.225 & - & & & & & \\
4. Perceived Control & 0.203 & -0.164 & $-0.341^{*}$ & - & & & & \\
5. Job Demand & 0.066 & 0.150 & -0.267 & 0.038 & - & & & \\
6. Social Support & -0.088 & 0.274 & 0.190 & -0.111 & $-0.368^{*}$ & - & & - \\
7. Self-esteem & 0.209 & -0.206 & -0.183 & 0.050 & 0.306 & -0.108 & - & - \\
8. Workplace Stress & -0.070 & -0.003 & -0.140 & -0.196 & 0.208 & 0.016 & -0.254 & $-0.336^{*}$ \\
9. Job Satisfaction & -0.207 & 0.148 & 0.149 & -0.046 & 0.092 & -0.014 & 0.153 & - \\
\hline
\end{tabular}

*Statistically significant correlation $(p<0.05$, two tailed). 
standard deviation of the model residuals was added in the simulation as a random noise. The mean value of response (job satisfaction) of the observations obtained from the survey was used as the low limit in the simulation. The number of simulation runs was set at 10,000 to improve the prediction accuracy. The simulation results gave the distribution of predicted response, desirability to achieve the expected outcome, and failure rate to meet the limit, either in percentage or ppm. The second scenario analyzed using the regression model was the work condition to achieve the highest level of job satisfaction. This was done by select "Maximize Desirability" function and the condition was automatically picked by JMP software.

\section{Results}

\subsection{Variable Distribution and Intercorrelation}

Scores from each item of the measurements (exogenous observed variables) were transformed into a common scale of $1-5$, and were averaged to give the results of each measurement. Table 2 lists the number of items of the measurements, means and standard deviations of the transformed measurement results, as well as the internal reliability results of the measurements.

The descriptive statistics of the variables are summarized in Table 4, which include sample size, mean, standard deviation, range, and 95\% confidence interval $(C I)$ of the mean. Correlation of the variables (Pearson's $r$ ) are summarized in Table 3, with the statistically significant correlations $(p<0.05)$ labeled. The results revealed that negative correlation occurred between social support and job demand $(r=-0.368, p<$ $0.05)$, perceived control and job conflict $(r=-0.341, p<0.05)$, and job satisfaction and self-rated stress ( $r=$ $-0.336, p<0.05)$.

\subsection{Linear Regression Model and Hypothesis Testing}

Multiple regression analysis was used to test if workplace stressors significantly predicted employees' job satisfaction. A regression model was constructed using the independent variables (or factors, which include years of experience, ambiguity, job conflict, perceived control, social support, job demands, self-esteem, and self-rated workplace stress) and their two-level interactions. The regression model was refined to contain only statistically significant terms (independent variables and their two-level interactions) using a backward stepwise approach. The regression is illustrated in the Actual by Predicted Plot in Figure 2. The regression is shown as a red solid line, with the $95 \%$ confidence interval as red dashed curves. The mean of the response (job satisfaction) was 3.80 from the 34 observations, which is shown as a horizontal blue dashed line. The distance to the horizontal blue dashed line (response mean) represents the residual to the baseline model, and the distance to the red solid line (regression line) represents the residual to the fitted model. In this case, the red dashed curves (95\% confidence interval of the regression) crossed the horizontal blue line (response mean), which implied that the regression model was statistically significant in explaining the variation of the data. The regression results indicated

Table 4. Distribution of variables.

\begin{tabular}{|c|c|c|c|c|c|}
\hline & $n$ & Mean & $S D$ & Sample Range & $95 \%$ CI \\
\hline Years of Experience & 40 & 10.25 & 5.99 & $5-25$ & $8.34-12.16$ \\
\hline Ambiguity & 41 & 3.11 & 0.75 & $1.33-4.61$ & $2.87-3.34$ \\
\hline Job Conflict & 42 & 3.07 & 0.58 & $2.00-4.49$ & $2.89-3.25$ \\
\hline Perceived Control & 40 & 3.05 & 0.53 & $1.94-4.16$ & $2.88-3.22$ \\
\hline Social Support & 40 & 4.10 & 0.50 & $3.08-5.00$ & $3.94-4.26$ \\
\hline Job Demands & 41 & 3.40 & 0.44 & $1.97-4.24$ & $3.26-3.54$ \\
\hline Job Satisfaction & 42 & 3.73 & 0.98 & $1.50-5.00$ & $3.43-4.04$ \\
\hline Self-Esteem & 42 & 3.97 & 0.61 & $2.70-5.00$ & $3.78-4.16$ \\
\hline Workplace Stress & 41 & 2.37 & 1.00 & $1.00-5.00$ & $2.05-2.68$ \\
\hline Demands & 40 & 3.19 & 0.38 & $2.32-4.20$ & $3.07-3.31$ \\
\hline Resources & 38 & 3.73 & 0.30 & $3.16-4.38$ & $3.63-3.82$ \\
\hline
\end{tabular}

$n$ = sample size; $S D$ = standard deviation; $C I$ = confidence interval. 


\section{Actual by Predicted Plot}

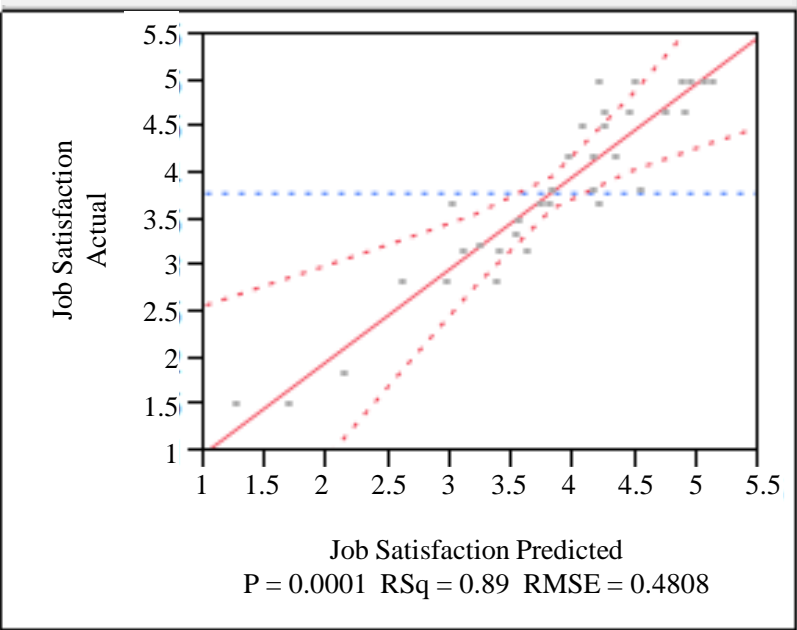

\begin{tabular}{ccccc}
\hline \multicolumn{5}{c}{ Summary of Fit } \\
\hline$R^{2}$ & Adjusted $R^{2}$ & $R M S E$ & Response Mean & Observations \\
\hline 0.89 & 0.76 & 0.48 & 3.80 & 34
\end{tabular}

\begin{tabular}{cccccc}
\hline \multicolumn{5}{c}{ ANOVA } & \\
\hline Model & Sum of Squares & $d f$ & Mean Square & $F$ & $p$ \\
\hline Regression & 28.499 & 17 & 1.676 & 7.251 & $0.0001^{*}$ \\
Residual & 3.699 & 16 & 0.231 & & \\
Total & 32.198 & 33 & & & \\
\hline
\end{tabular}

Figure 2. Summary of the linear regression model. Independent variables include years of experience, ambiguity, job conflict, perceived control, social support, job demands, self-esteem, and (self-rated) workplace stress; dependent variable: job satisfaction; RMSE = root mean square error; $\mathrm{df}=$ degree of freedom; *regression model is statistically significant $(p<0.05)$; blue dashed line $=$ mean of the response (job satisfaction); red dashed curves $=95 \%$ confidence interval; red solid line $=$ regression line.

that the independent variables and their two-level interactions significantly predicted job satisfaction, which explained $89 \%$ of the variance $\left(R^{2}=0.89, F(17,16)=7.251, p=0.0001\right)$ (Figure 2). The $R^{2}$ value depicted the goodness of fit of the model, and the adjusted $R^{2}$ was a modification of $R^{2}$ that adjusted for the number of explanatory terms (factors and two-level interactions used in the model, as listed in Table 5) in the model. In this case, both the $R^{2}(0.89)$ and the adjusted $R^{2}(0.76)$ are high, indicating good model fitting. The multi-collinearity was assessed by the variable inflation factor (VIF); the terms with a VIF value of 8 and above were removed to avoid over fitting. In the constructed regression model, all the terms have VIF values below 8 (Table 5). In addition, the Durbin-Watson value was calculated to detect the presence of autocorrelation in the residuals, which was 2.3, between the acceptable range of 1.5 and 2.5 [6].

The characteristics of the regression model are summarized in Table 5, which include unstandardized coefficient $(B)$, standardized coefficient $(\beta)$, effect size, $t$-ratio, and $p$-value of the independent variables and their interactions. The interaction between perceived control and job demand and interaction between self-rated stress and job conflict had the biggest effect size on job satisfaction. Though perceived control and self-esteem did not show statistically significant effects by themselves, the interactions between them and other variables (such as self-rated stress) showed a statistical effect on job satisfaction. The constructed regression model can be used to predict employee job satisfaction under different working conditions. 
Table 5. Regression coefficients and collinearity of independent variables and interactions.

\begin{tabular}{|c|c|c|c|c|c|c|c|}
\hline \multirow{2}{*}{ Independent Variable and Interaction } & \multicolumn{2}{|c|}{$\begin{array}{l}\text { Unstandardized } \\
\text { Coefficient }\end{array}$} & \multirow{2}{*}{$\begin{array}{c}\begin{array}{c}\text { Standardized } \\
\text { Coefficient }\end{array} \\
\beta\end{array}$} & \multirow{2}{*}{$\begin{array}{l}\text { Effect } \\
\text { Size }^{a}\end{array}$} & \multirow[t]{2}{*}{$t$ Ratio } & \multirow{2}{*}{$p$} & \multirow[t]{2}{*}{ VIF } \\
\hline & $B$ & $S E$ & & & & & \\
\hline Intercept & -1.161 & 1.682 & 0 & 6.855 & -0.69 & 0.4999 & \\
\hline Years of Experience & -0.123 & 0.021 & -0.705 & -2.469 & -5.77 & $<0.0001^{*}$ & 2.080 \\
\hline Self-esteem & -0.265 & 0.201 & -0.172 & -0.608 & -1.32 & 0.2070 & 2.386 \\
\hline Workplace Stress & -0.514 & 0.107 & -0.556 & -2.054 & -4.81 & $0.0002^{*}$ & 1.865 \\
\hline Ambiguity & -0.419 & 0.148 & -0.335 & -1.373 & -2.84 & $0.0119^{*}$ & 1.948 \\
\hline Job Conflict & 0.482 & 0.196 & 0.269 & 1.105 & 2.46 & $0.0256^{*}$ & 1.660 \\
\hline Perceived Control & -0.067 & 0.191 & -0.037 & -0.148 & -0.35 & 0.7320 & 1.566 \\
\hline Job Demand & 2.413 & 0.377 & 1.116 & 5.476 & 6.41 & $<0.0001^{*}$ & 4.221 \\
\hline (Years of Experience-10) * (Self-esteem-3.90458) & 0.284 & 0.051 & 1.141 & 6.536 & 5.55 & $<0.0001^{*}$ & 5.890 \\
\hline (Years of Experience-10) * (Workplace Stress-2.37255) & 0.067 & 0.023 & 0.426 & 2.666 & 2.88 & $0.0109^{*}$ & 3.053 \\
\hline (Years of Experience-10) * (Job Conflict-3.17419) & 0.273 & 0.063 & 0.769 & 6.265 & 4.34 & $0.0005^{*}$ & 4.358 \\
\hline (Self-esteem-3.90458) * (Workplace Stress-2.37255) & -1.003 & 0.231 & -0.667 & -4.613 & -4.34 & $0.0005^{*}$ & 3.285 \\
\hline (Self-esteem-3.90458) * (Perceived Control-3.01374) & -2.250 & 0.426 & -0.782 & -5.742 & -5.28 & $<0.0001^{*}$ & 3.053 \\
\hline (Workplace Stress-2.37255) * (Ambiguity-3.17271) & 0.980 & 0.183 & 0.759 & 6.416 & 5.35 & $<0.0001^{*}$ & 2.801 \\
\hline (Workplace Stress-2.37255) * (Job Conflict-3.17419) & -1.525 & 0.317 & -0.776 & -6.990 & -4.81 & $0.0002^{*}$ & 3.617 \\
\hline (Workplace Stress-2.37255) * (Perceived Control-3.01374) & -1.274 & 0.306 & -0.744 & -5.652 & -4.16 & $0.0007^{*}$ & 4.459 \\
\hline (Job Conflict-3.17419) * (Perceived Control-3.01374) & 2.448 & 0.612 & 0.697 & 6.224 & 4 & $0.0010^{*}$ & 4.239 \\
\hline (Perceived Control-3.01374) * (Job Demand-3.34626) & 3.245 & 0.662 & 0.866 & 8.169 & 4.9 & $0.0002^{*}$ & 4.345 \\
\hline
\end{tabular}

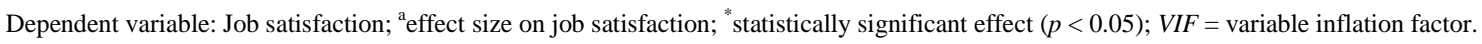

\subsection{Monte Carlo Simulation}

The constructed regression model was further used in Monte Carlo simulation to predict the outcome of response (job satisfaction) under different work condition scenarios. Figure 3 illustrates an example on how the simulation was performed with the measured results. The prediction profiler is shown in the top row of graphs listed, with each independent variable as the $\mathrm{X}$-axis and the job satisfaction, the response, as the Y-axis. As the settings of independent variables (vertical red dashed line) changed, the corresponding response (horizontal red dashed line) was predicted by the model. The prediction trace (black solid line) and 95\% confidence interval (blue dashed curves) are shown in each graph. The desirability profiler is shown in the second row of the graphs, with each independent variable as the $\mathrm{X}$-axis and the desirability (for the response), on a scale of $0-1$, as the Y-axis. The horizontal red dashed lines in these graphs depict the desirability for the response, the level of job satisfaction. The goal was to maximize the level of job satisfaction. The third row of the graphs illustrates the distribution of the independent variables, based on the distribution data summarized in Table 4. In this case, the mean values and standard deviations of the independent variables were used to simulate the level of job satisfaction. To compensate for the uncontrolled variations, a random noise of 0.335 was added in the simulation. This value was the standard deviation of model residuals. The mean value of job satisfaction of the 34 observations, 3.80 , was used as the low limit in the simulation. The number of runs was set at 10,000. The predicted response is shown in the desirability graphs, with predicted distribution of predicted response and desirability. The predicted mean value of job satisfaction was 3.40, with a standard deviation of 2.06. The defect rate was predicted to be 0.59 , which indicated that $59 \%$ of the employees in the organization would have a job satisfaction level below the mean value of 3.80 , under the current work conditions.

Another simulation was performed to find out the work conditions that potentially lead to the highest level of job satisfaction, which is illustrated in Figure 4. The simulation suggested that employees with 25 years of working experience, under low levels of ambiguity (1.3) and self-rated stress (1.0), and high levels of self-esteem (5.0), perceived control (4.2), job conflict (4.5), and job demand (4.2), would have the highest level of job 

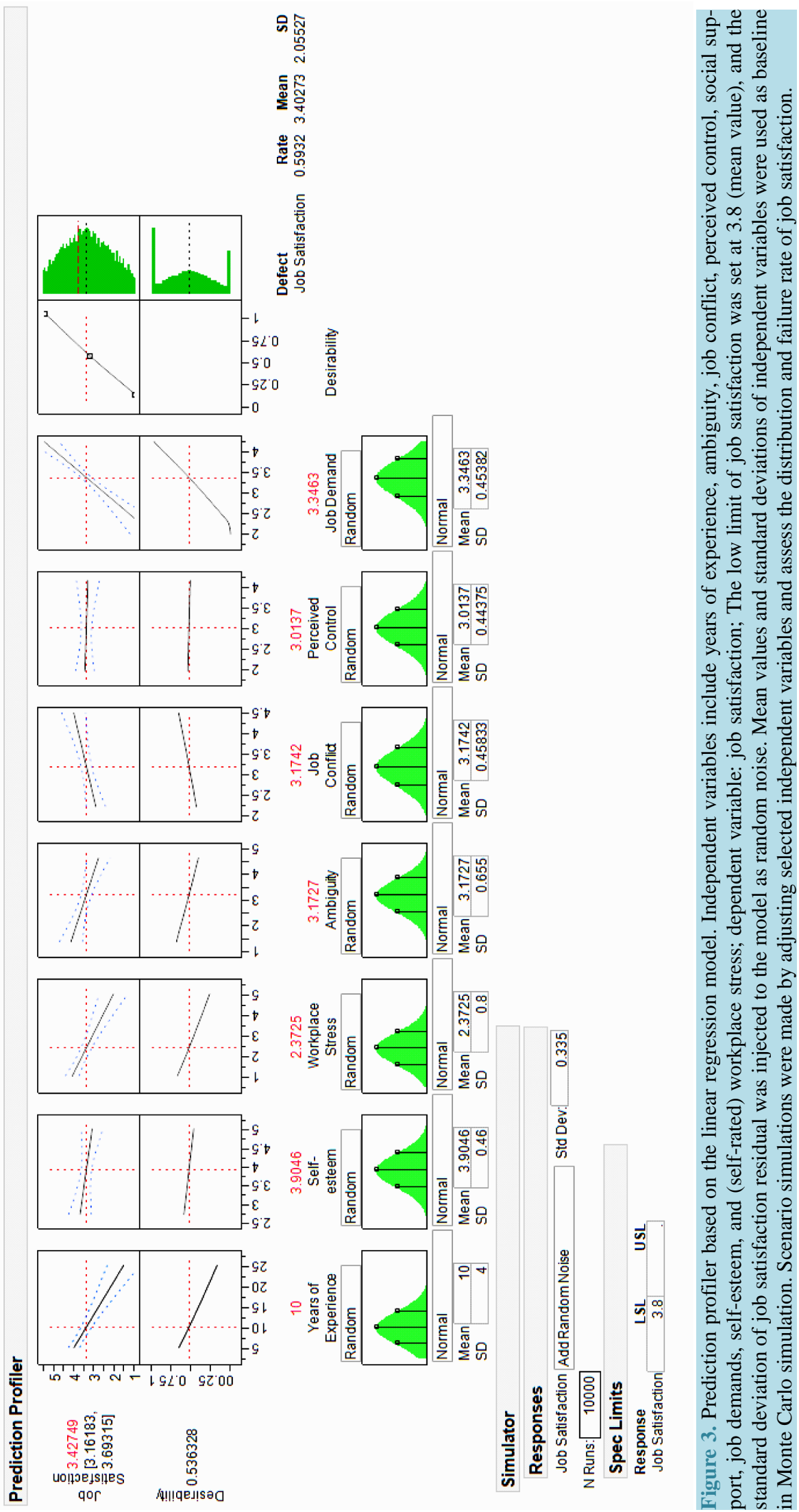


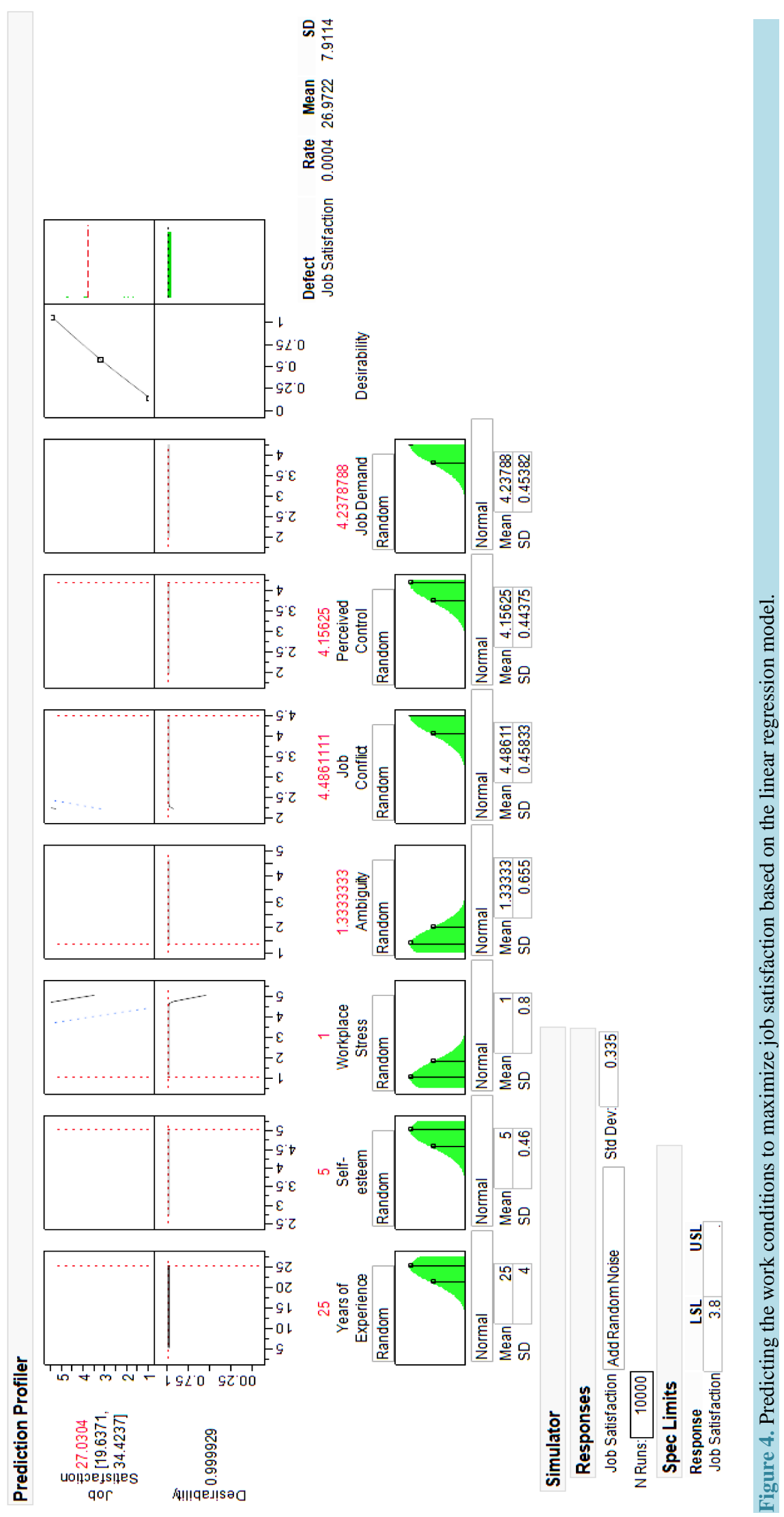


satisfaction. The predicted mean value of job satisfaction was 27.0, with a standard deviation of 7.91. The defect rate was predicted to be 0.00 , which indicated that none of the employees in the organization would have a job satisfaction level below the mean value of 3.80 , under this scenario. This was predicted based only on the regression model from available data, which needs to be verified in real situation.

\section{Discussion}

Workplace stress is a common problem with broad effects in professional life. It is important to gain a better understanding of work-related stress and its effects on employee job satisfaction. Although a number of studies suggested negative association between workplace stress and job satisfaction, the studies on workplace stress are "hindered by lack of understanding of how sources of stress vary between different practice areas, lack of predictive power of assessment tools, and a lack of understanding of how personal and workplace factors interact”(p. 633) [9]. To our knowledge, there was no report specifically on biologics development professionals. This group of professionals is actively engaged in the discovery, development, manufacture and commercialization of biologics (medical products made from living systems), such as recombinant proteins, monoclonal antibodies, vaccines, and blood products [23]. This is a rapidly growing industry. Based on the Pharmaceutical Research and Manufacturers of America [24], the US biotechnology companies "are developing 907 biologics targeting more than 100 diseases” (p. 1). Biologics development professionals typically spend most of their time in laboratories developing new biological products. Their work involves high levels of challenge and uncertainty. Due to the unique nature of their working conditions, it was necessary to tailor the study specifically to this group of professionals. This study was the first report that provided comprehensive quantitative analyses on workplace stressors and their effects on the level of job satisfaction among biologics development professionals at a particular organization. The constructed statistical model allowed us to simulate the working conditions and predict the job satisfaction levels under different work conditions. The findings of this study may provide guidance to develop strategies to improve employee job satisfaction in this organization. In addition, this may serve to help establish the baseline for further longitudinal studies within the organization.

Like other empirical studies, this study has a number of limitations. First, this study was limited by the small population size in a specific setting. The findings of this study may not apply to the general population of biologics development professionals. Second, the survey was delivered online with e-mail notification, which has the drawback of low response rate and self-selection bias [25]. Third, the Cronbach's $\alpha$ of perceived control and task control has low values. The perceived control in the survey instrument was assessed by only two questions, which resulted in low consistency in responses. The low value in task control, on the other hand, may reflect the nature of the research and development working environment with a lot of uncertainties. In addition to these limitations, the survey instruments were modified when the survey questionnaires were developed. The modifications include selection of the stress items in the DASS-21 Questionnaire [20] to measure self-rated stress, exclusion of items unrelated to the studied variables from the NIOSH Questionnaire [17], conversion of the measured scores to a common scale of $1-5$, and change the data type of work experience from nominal to scale. It was possible that these changes may affect the overall reliability and validity of the study. Finally, the survey results only reflect the situation under the specific conditions at one particular time and setting. Thus, further studies with a larger sample size, improved and more specific survey instruments, and repeated measures at multiple settings are needed to further understand the workplace conditions that affect job satisfaction among biologics development professionals.

Nonetheless, this study was the first to measure workplace stressors and quantify the effects of such stressor on job satisfaction among biologics development professionals within this organization. The results suggested that the workplace stressors significantly predicted the level of job satisfaction. The interaction between perceived control and job demand and interaction between self-rated stress and job conflict had the biggest effect size on the level of job satisfaction. The simulation results in Figure 4 suggested that experienced employees with high self-esteem and low self-rated stress, under working conditions with low ambiguity, high perceived control, and challenged with high job conflict and job demand, would have the highest level of job satisfaction. This may reflect the characteristics of some highly experienced professionals whose job satisfaction relies on meeting the challenges in their daily work. Simulations in Figure 3 and Figure 4 served as two examples to illustrate two scenarios and corresponding levels of job satisfaction. More simulations could be conducted to predict job satisfaction under other scenarios. For example, the years of experience could be fixed, and other inde- 
pendent variables are varied to find out conditions that maximize the job satisfaction level for employees with specific years of experience. The findings of this study helped to establish a baseline to measure the work condition and corresponding job satisfaction within the organization studied. This may assist management in identifying ways to improve employee job satisfaction.

Although regression analysis results revealed the correlation relationship between the independent variables and dependent variable, the causal relationships among the variables cannot be determined. Thus, it is recommended to verify the findings of this study in real situations, and continue to monitor in longitudinal studies. In addition, further studies with increased sample size at different biologics development organizations are needed to further elucidate the predictors for job satisfaction for general working population in this industry.

\section{Conclusion}

The results of this study revealed that the workplace stressors have significant effect on employees' level of job satisfaction within the organization studied. Under the current work condition, 59\% of the employees in the organization had a job satisfaction level below the mean value of 3.80. The conditions to achieve the highest level of job satisfaction were predicted in Monte Carlo simulation, which include employees with long working experience, under low levels of ambiguity, self-rated stress, and high levels of self-esteem, perceived control, job conflict, and job demand. This was an early stage study due to the limitations; however, it serves to establish a baseline to measure the working conditions and corresponding job satisfaction for further longitudinal studies at the particular setting under study. The findings may guide the management to develop an environment that supports improved job satisfaction. Further studies with a larger population at different settings are needed to elucidate the predictors for job satisfaction for general working populations in this industry.

\section{References}

[1] Bhui, K.S., Dinos, S., Stansfeld, S.A. and White, P.D. (2012) A Synthesis of the Evidence for Managing Stress at Work: A Review of the Reviews Reporting on Anxiety, Depression, and Absenteeism. Journal of Environmental and Public Health, 2012, 1-21. http://dx.doi.org/10.1155/2012/515874

[2] European Agency for Safety and Health at Work (2009) OSH in Figures: Stress at Work-Facts and Figures. http://osha.europa.eu/en/publications/reports/TE-81-08-478-EN-C_OSH_in_figures_stress_at_work

[3] Demerouti, E., Bakker, A.B., Nachreiner, F. and Schaufeli, W.B. (2000) A Model of Burnout and Life Satisfaction amongst Nurses. Journal of Advanced Nursing, 32, 454-464. http://dx.doi.org/10.1046/j.1365-2648.2000.01496.x

[4] Hakanen, J.J., Bakker, A.B. and Schaufeli, W.B. (2006) Burnout and Work Engagement among Teachers. Journal of School Psychology, 43, 495-513. http://dx.doi.org/10.1016/j.jsp.2005.11.001

[5] Jourdain, G. and Chenevert, D. (2010) Job Demands-Resources, Burnout and Intention to Leave the Nursing Profession: A Questionnaire Survey. International Journal of Nursing Studies, 47, 709-722. http://dx.doi.org/10.1016/j.ijnurstu.2009.11.007

[6] Iqbal, M. and Waseem, M.A. (2012) Impact of Job Stress on Job Satisfaction among Air Traffic Controller of Civil Aviation Authority: An Empirical Study from Pakistan. International Journal of Human Resource Studies, 2, 53-69. http://dx.doi.org/10.5296/ijhrs.v2i2.1854

[7] Stordeur, S., D’hoore, W. and Vandenberghe, C. (2001) Leadership, Organizational Stress, and Emotional Exhaustion among Hospital Nursing Staff. Journal of Advanced Nursing, 35, 533-542. http://dx.doi.org/10.1046/j.1365-2648.2001.01885.x

[8] Blaug, R., Kenyon, A. and Lekhi, R. (2007) Stress at Work: A Report Prepared for the Work Foundation's Principal Partners. http://www.theworkfoundation.com/downloadpublication/report/69_69_stress_at_work.pdf

[9] McVicar, A. (2003) Workplace Stress in Nursing: A Literature Review. Journal of Advanced Nursing, 44, $633-642$. http://dx.doi.org/10.1046/j.0309-2402.2003.02853.x

[10] World Health Organization (2012) Stress at the Workplace. http://www.who.int/occupational_health/topics/stressatwp/en/

[11] Dollard, M.F. and Winefield, A.H. (2002) Mental Health: Overemployment, Underemployment, Unemployment and Healthy Jobs. Australian e-Journal for the Advancement of Mental Health, 1, 1-26.

[12] New Zealand Department of Labour (n.d.) Models of Stress. http://www.osh.govt.nz/publications/booklets/stress-tools2008/models-stress.asp

[13] Carter, K.N., Blakely, T., Collings, S., Gunasekara, F.I. and Richardson, K. (2009) What Is the Association between 
Wealth and Mental Health? Journal of Epidemiology Community Health, 63, 221-226. http://dx.doi.org/10.1136/jech.2008.079483

[14] Levy, A. (2007) Wealth, Social Capital and Happiness: The Case of Status Sensitive People. http://www.uow.edu.au/commerce/econ/wpapers.html

[15] Maestripieri, D. (2012) Gender Differences in Responses to Stress: It Boils Down to a Single Gene. Psychology Today. http://www.psychologytoday.com/blog/games-primates-play/201203/gender-differences-in-responses-stress-it-boils-do wn-single-gene

[16] MacDonald, L.A., Deddens, J.A., Grajewski, B.A., Whelan, E.A. and Hurrell, J.J. (2003) Job Stress among Female Flight Attendants. Journal of Occupational and Environmental Medicine, 45, 703-714. http://dx.doi.org/10.1097/01.jom.0000071509.96740.dd

[17] National Institute of Occupational Safety and Health (2008) NIOSH Generic Job Stress Questionnaire. http://www.cdc.gov/niosh/topics/workorg/tools/niosh-job-stress-questionnaire.html

[18] Hurrell Jr., J.J. and McLaney, M.A. (1988) Exposure to Job Stress-A New Psychometric Instrument. Scandinavian Journal of Work Environmental Health, 14, 27-28.

[19] D’Amato, A. and Zijlstra, F.R.H. (2003) Occupational Stress: A Review of the Literature Relating to Mental Health. Stress Impact: Work Package. http://www.fahs.surrey.ac.uk/stress_impact/publications/wp1/WP1-Ch2_Stress\%20Impact\%20literature2.pdf

[20] Depression Anxiety Stress Scale (n.d.) DASS FAQ. http://www2.psy.unsw.edu.au/dass/DASSFAQ.htm

[21] Henry, J.D. and Crawford, J.R. (2005) The Short-Form Version of the Depression Anxiety Stress Scales (DASS-21): Construct Validity and Normative Data in a Large Non-Clinical Sample. British Journal of Clinical Psychology, 44, 227-239. http://dx.doi.org/10.1348/014466505X29657

[22] IBM (2010) Transforming Different Likert Scales to a Common Scale. http://www-01.ibm.com/support/docview.wss?uid=swg21482329

[23] Food and Drug Administration (2010) What Is a Biological Product? http://www.fda.gov/AboutFDA/Transparency/Basics/ucm194516.htm

[24] Pharmaceutical Research and Manufacturers of America (2013) Medicines in Development: Biologics. http://www.phrma.org/sites/default/files/pdf/biologics2013.pdf.

[25] Portney, L.G. and Watkins, M.P. (2009) Foundations of Clinical Research: Applications to Practice. 3rd Edition, Prentice Hall, Upper Saddle River. 
Scientific Research Publishing (SCIRP) is one of the largest Open Access journal publishers. It is currently publishing more than 200 open access, online, peer-reviewed journals covering a wide range of academic disciplines. SCIRP serves the worldwide academic communities and contributes to the progress and application of science with its publication.

Other selected journals from SCIRP are listed as below. Submit your manuscript to us via either submit@scirp.org or Online Submission Portal.
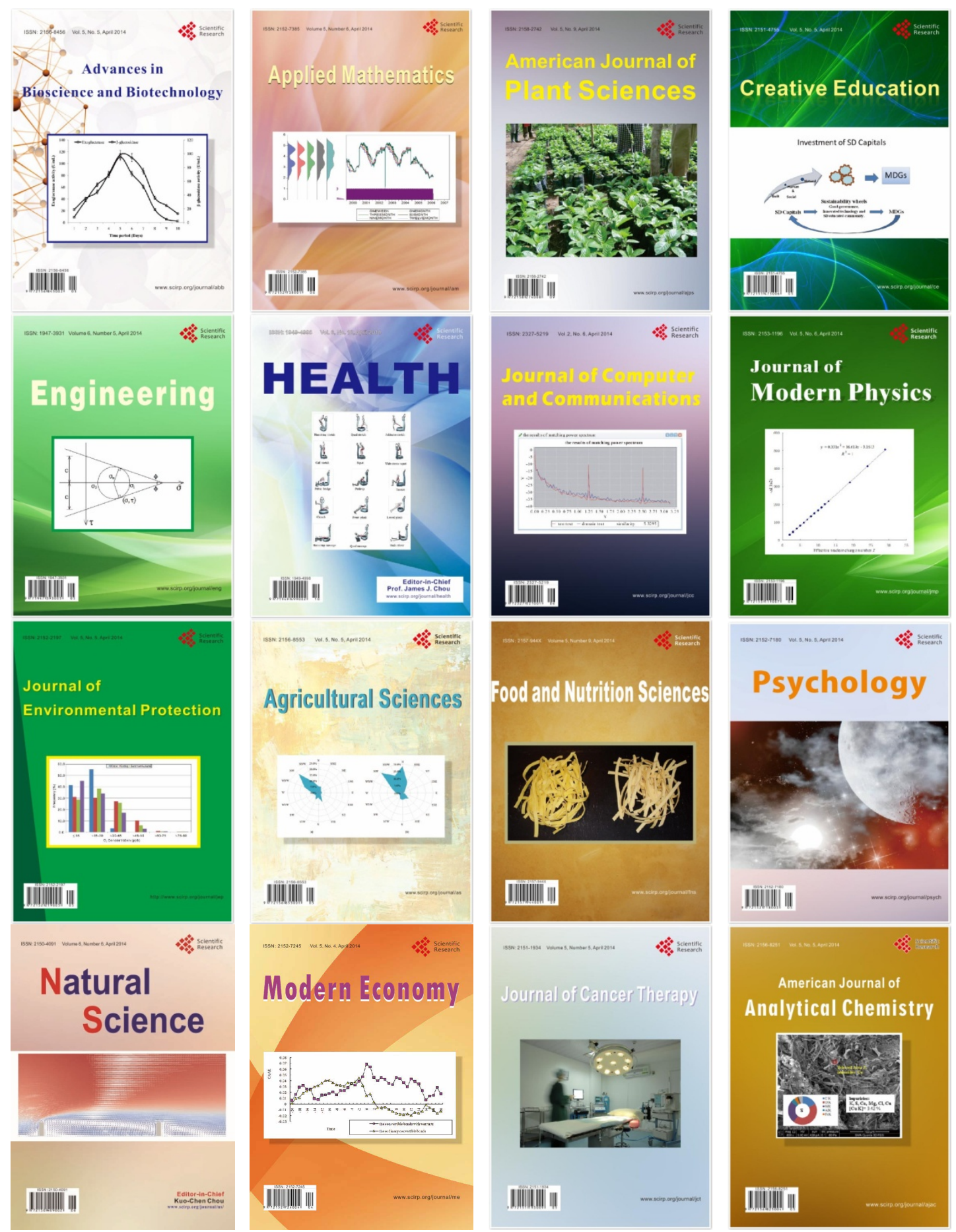